\title{
Opinion \& Special Articles: Competency in Serious Illness Communication for Neurology Residents
}

Tarini Goyal, MD, Maisha T. Robinson, MD, MS, and Carl A. Gold, MD, MS

Neurology ${ }^{\circledR} 2021 ; 96: 587-589$. doi:10.1212/WNL.0000000000011048

\author{
Correspondence \\ Dr. Gold \\ carlgold@stanford.edu
}

Until 2019, the only reference that the Accreditation Council for Graduate Medical Education (ACGME) made to discussion of patients' care values was an indirect one: that neurology residents must "demonstrate knowledge of palliative care, including adequate pain relief as well as psychosocial support and counseling for patients and families." In 2009, a nationwide study demonstrated neurology residents' poor knowledge of palliative care across multiple domains, including discussing end-of-life care preferences. ${ }^{2}$

Ten years later, the 2019 ACGME program requirements recommended for the first time that neurology residents demonstrate competency in assessing patients' "care goals, including, when appropriate, end-of-life goals." This is an important step in the right direction. However, the explanation of the new competency continues: "When there are no more medications or interventions that can achieve a patient's goals or provide meaningful improvements in quality or length of life, a discussion about the patient's goals, values, and choices surrounding the end of life is one of the most important conversations that can occur." 3 By positioning the elicitation of care preferences as a last resort, opportunities to improve quality of life throughout the course of illness may be missed. The ACGME should make clear that care values and preferences can and should be discussed with patients with progressive or disabling conditions regardless of their age or stage of disease, and that neurologists should be trained to routinely incorporate this aspect of primary palliative care into their practice. ${ }^{4,5}$

There is a substantial need for palliative care in patients with neurologic conditions from the time of diagnosis until the end of life. Key palliative care skills for the neurologist include managing symptoms, supporting caregivers, and having serious illness conversationsdelivering serious news, communicating prognosis, and discussing preferences for care and treatment with patients and surrogate decision-makers throughout the trajectory of disease. ${ }^{4}$ Discussion of patients' health values only near the end of life carries the risk of being too little, too late, with patients potentially receiving treatments that may not align with their preferences for care.

The need for early and adequate serious illness conversations with patients with neurologic conditions is markedly different from neurology residency curricula and training requirements in these skills. To meet residents' learning needs as well as the new standard set by the ACGME, programs must incorporate serious illness communication training. To support residency programs, the ACGME and other educational regulatory bodies in neurology should lead the way in promoting comprehensive palliative care education for neurologists-in-training, rather than endorsing an antiquated view of the role of serious illness conversations and other aspects of palliative care in neurology as only occurring at the end of life.

\footnotetext{
From the Department of Neurology \& Neurological Sciences (T.G., C.A.G.), Stanford University School of Medicine, CA; and Department of Neurology (M.T.R.), Mayo Clinic, Jacksonville, FL. 


\section{The Current State of Training}

Neurology trainees are not being appropriately prepared to provide primary palliative care, which includes leading serious illness conversations. Almost half of surveyed neurology residency program directors rated their own palliative care curricula as inadequate, and one-fifth reported having no palliative care education at all. ${ }^{6}$ Most believed that formal didactics such as seminars and conferences were an ineffective method of teaching palliative care skills, but these were also the most commonly deployed methods. Program directors rated the importance of learning serious illness communication skills as high and residents' skills as low. Perceived barriers included teaching time, faculty availability, and educational resources. The variation in content, delivery, and assessment of serious illness communication and other palliative care skills suggest that the 2009 ACGME requirements did not serve as an adequate guide for curriculum development. ${ }^{6}$

Neurology residents have also identified multiple barriers to learning effective serious illness communication skills, including lack of neurology-specific training in prognosticating, communicating with surrogate decision-makers, and navigating multiple decision points in care. ${ }^{7}$ Further, programmatic factors such as limited direct observation and feedback about serious illness conversations hinder residents' ability to actively improve. $^{7}$

\section{Next Steps for Residency Programs}

In order to meet the new minimum requirement of competency in discussing end-of-life care preferences, pragmatic education and assessment of serious illness communication should be integrated into neurology graduate medical education. Depending on a program's needs, this may range from individual resident self-study to experiential learning to a formal didactic curriculum. Online courses such as VitalTalk and the Education in Palliative and End-Of-Life Care program include short modules that residents can complete on their own, to be used alone or to supplement other teaching modalities. ${ }^{8,9} \mathrm{Re}-$ cent textbooks on neuropalliative care can serve as both references and case studies to be worked through individually or as part of a curriculum. ${ }^{10,11}$ In the hospital and clinic settings, the palliative care service is an underutilized educational resource as fewer than one-quarter of surveyed neurology residency programs offer an elective rotation with palliative care. ${ }^{6}$ Clinical rotations with palliative care faculty have been shown to foster serious illness communication skills, as residents are more likely to be provided intentional feedback and graduated independence around these skills. ${ }^{12}$

Finally, individual residency programs may utilize the strengths of their own faculty when appropriate. Though neurology faculty members may not have formal palliative care training, they may be interested in teaching serious illness communication within their subspecialty. For example, neurointensivists could teach about discussing prognosis after acute brain injury, neuromuscular specialists could discuss clinical decision points across the course of caring for patients with amyotrophic lateral sclerosis, and neuro-oncologists could share how they re-evaluate patients' preferences for care when they develop brain tumor recurrence. By implementing this strategy at our own institution, a brief curriculum has improved residents' self-evaluated comfort with serious illness conversations. A more extensive, 14-week curriculum covering multiple domains of primary palliative care relevant to neurology has also shown improvement in residents' selfconfidence. $^{13}$

When incorporating new milestones, residency programs must modify their educational methods and assessment tools to determine whether residents have achieved competency. ${ }^{14}$ Any of these educational strategies can be paired with neuropalliative care-specific objective structured clinical examinations (OSCEs), which require investment of program time and resources, but serve as simultaneous education, assessment, and feedback. OSCEs are often conducted with standardized patients; however, peer role play with feedback is an economical strategy that has been shown to be equally effective and to have specific benefits in fostering empathy for the patient's perspective. ${ }^{15}$ To assess communication skills, direct observation is accurate, useful, and less resource-intensive than more artificial assessment measures. ${ }^{14}$ Ideally, patient and family experiences are also incorporated as part of 360-degree feedback over time. Programmatic assessment such as the Clinical Skills Evaluations and residency in-service examinations serve as another opportunity for multimodal assessment. We recommend that as immediate next steps, residency programs (1) assess departmental and institutional resources for teaching serious illness communication skills, (2) select a primary educational method such as online modules, didactic curriculum, or focused clinical rotation, and (3) select a primary method of assessment.

\section{What Neurology Trainees Can Do Now}

The voice of neurology residents may be influential for demonstrating the value of serious illness communication training to residency program leadership and to the larger neurology community. As an initial action step, residents can advocate to incorporate online modules or other dedicated serious illness communication training into their residency education. Residents can also pursue elective rotations in palliative care and request an emphasis on neurology cases and communication training and feedback. Residents can participate in palliative care courses at national meetings such as the American Academy of Neurology annual meeting. Finally, residents who are interested in further training in all aspects of palliative care should explore opportunities for fellowship training in hospice and palliative medicine as well as new opportunities for neuropalliative care fellowship. 


\section{The ACGME Can Help}

The ACGME competencies and neurology-specific milestones are intended to guide how residency programs evaluate and demonstrate trainees' readiness for graduation and independent practice. The new milestone is essential, but it is not enough. Given the important role that competencies play in motivating curricular design, we propose that the ACGME use updated language mirroring that which is already found in the palliative medicine fellowship competencies, and is highly applicable to neurology: that trainees "must demonstrate competence in providing palliative care throughout the continuum of serious illness...facilitating patient autonomy, access to information, and choice" to optimize quality of life. ${ }^{16}$

Including palliative care questions on the American Board of Psychiatry and Neurology initial certification examination for neurology would further incentivize residency programs to incorporate serious illness communication training into the curriculum. The content of the neurology board examinations includes communication and end-of-life issues, but should be made more specific and comprehensive, addressing multiple domains of neuropalliative care.

Residency programs and the ACGME are poised to effect meaningful change in the way we teach neurology residents to approach serious illness conversations. If these essential skills in neuropalliative care are emphasized during training, the next generation of neurologists will be wellequipped to care for our patients with chronic, advanced, and serious illnesses from the time of diagnosis to the end of life.

\section{Study Funding}

No targeted funding reported.

\section{Disclosure}

T. Goyal reports no disclosures relevant to the manuscript. M.T. Robinson receives royalties for publishing from Cambridge University Press. C.A. Gold reports no disclosures relevant to the manuscript. Go to Neurology.org/ $\mathrm{N}$ for full disclosures.

\begin{tabular}{lll} 
Appendix & Authors & \\
\hline Name & Location & Contribution \\
\hline $\begin{array}{l}\text { Tarini } \\
\text { Goyal, MD }\end{array}$ & $\begin{array}{l}\text { Department of Neurology, } \\
\text { Columbia University, New } \\
\text { York, NY }\end{array}$ & $\begin{array}{l}\text { Design or conceptualization } \\
\text { of study, drafting and } \\
\text { revising the manuscript for } \\
\text { intellectual content }\end{array}$ \\
\hline $\begin{array}{l}\text { Maisha T. } \\
\text { Robinson, }\end{array}$ & $\begin{array}{l}\text { Department of Neurology, } \\
\text { Mayo Clinic, Jacksonville, FL }\end{array}$ & $\begin{array}{l}\text { Drafting or revising the } \\
\text { manuscript for intellectual } \\
\text { content }\end{array}$ \\
\hline $\begin{array}{l}\text { Carl A. } \\
\text { Gold, MD, } \\
\text { MS }\end{array}$ & $\begin{array}{l}\text { Department of Neurology \& } \\
\text { Neurologic Sciences, }\end{array}$ & $\begin{array}{l}\text { Design or conceptualization } \\
\text { of study, drafting and } \\
\text { revising the manuscript for } \\
\text { intellectual content }\end{array}$ \\
\hline
\end{tabular}

\section{References}

1. ACGME Program Requirements for Graduate Medical Education in Neurology [online]. Available at: residents.lsuhsc.edu/no/neurology/docs/Neurology\%20Requirements\%207-1-2017.pdf. Accessed February 8, 2020

2. Creutzfeldt CJ, Gooley T, Walker M. Are neurology residents prepared to deal with dying patients? Arch Neurol 2009;66:1427-1429.

3. ACGME Program Requirements for Graduate Medical Education in Neurology [online]. Available at: acgme.org/Portals/0/PFAssets/ProgramRequirements/180_ Neurology_2019_TCC.pdf. Accessed February 8, 2020.

4. Boersma I, Miyasaki J, Kutner J, Kluger B. Palliative care and neurology: time for a paradigm shift. Neurology 2014;83:561-567.

5. Creutzfeldt CJ, Robinson MT, Holloway RG. Neurologists as primary palliative care providers: communication and practice approaches. Neurol Clin Pract 2016;6:40-48.

6. Mehta AK, Najjar S, May N, Shah B, Blackhall L. A needs assessment of palliative care education among the United States Adult Neurology Residency Programs. J Palliat Med 2018;21:1448-1457.

7. Goyal T, Hasty BN, Bereknyei Merrell S, Gold CA. Education research: understanding barriers to goals of care communication for neurology trainees. Neurology 2019;93:362-366.

8. VitalTalk [online]. Available at: vitaltalk.org/. Accessed April 26, 2020.

9. Education in Palliative and End-Of-Life Care [online]. Available at: bioethics. northwestern.edu/programs/epec/. Accessed July 26, 2020.

10. Creutzfeldt C, Kluger BM, Holloway RG. Neuropalliative Care: A Guide to Improving the Lives of Patients and Families Affected by Neurologic Disease. Switzerland: Springer; 2019.

11. Robinson MT, ed. Case Studies in Neuropalliative Care. New York: Cambridge University Press; 2018.

12. Kurahashi AM, Wales J, Husain A, Mahtani R. Residents' reflections on end-of-life conversations: how a palliative care clinical rotation creates meaningful learning opportunities. Ann Palliat Med 2020;9:738-745.

13. Schuh LA, Biondo A, An A, et al. Neurology resident learning in an end-of-life/ palliative care course. J Palliat Med 2007;10:178-181.

14. Jones LK Jr. Assessment in neurologic education. Semin Neurol 2018;38:471-478.

15. Bosse HM, Schultz JH, Nickel M, et al. The effect of using standardized patients o peer role play on ratings of undergraduate communication training: a randomized controlled trial. Patient Educ Couns 2012;87:300-306.

16. ACGME Program Requirements for Graduate Medical Education in Hospice and Palliative Medicine [online]. Available at: acgme.org/Portals/0/PFAssets/ProgramRequirements/540_HospicePalliativeMedicine_2019.pdf. Accessed February $29,2020$.

\section{Subspecialty Alerts by E-mail!}

Customize your online journal experience by signing up for e-mail alerts related to your subspecialty or area of interest. Access this free service by clicking on the "My Alerts" link on the home page. An extensive list of subspecialties, methods, and study design choices will be available for you to choose from-allowing you priority alerts to cutting-edge research in your field! 


\section{Neurology}

Opinion \& Special Articles: Competency in Serious Illness Communication for Neurology Residents

Tarini Goyal, Maisha T. Robinson and Carl A. Gold

Neurology 2021;96;587-589 Published Online before print October 14, 2020

DOI 10.1212/WNL.0000000000011048

This information is current as of October 14, 2020

\section{Updated Information \& \\ Services}

\section{References}

Subspecialty Collections

Permissions \& Licensing

Reprints including high resolution figures, can be found at: http://n.neurology.org/content/96/12/587.full

This article cites 9 articles, 3 of which you can access for free at: http://n.neurology.org/content/96/12/587.full\#ref-list-1

This article, along with others on similar topics, appears in the following collection(s): Methods of education

http://n.neurology.org/cgi/collection/methods_of_education

Palliative care

http://n.neurology.org/cgi/collection/palliative_care

Information about reproducing this article in parts (figures,tables) or in its entirety can be found online at:

http://www.neurology.org/about/about_the_journal\#permissions

Information about ordering reprints can be found online:

http://n.neurology.org/subscribers/advertise

Neurology $\AA$ is the official journal of the American Academy of Neurology. Published continuously since 1951, it is now a weekly with 48 issues per year. Copyright (C) 2020 American Academy of Neurology. All rights reserved. Print ISSN:

0028-3878. Online ISSN: 1526-632X.

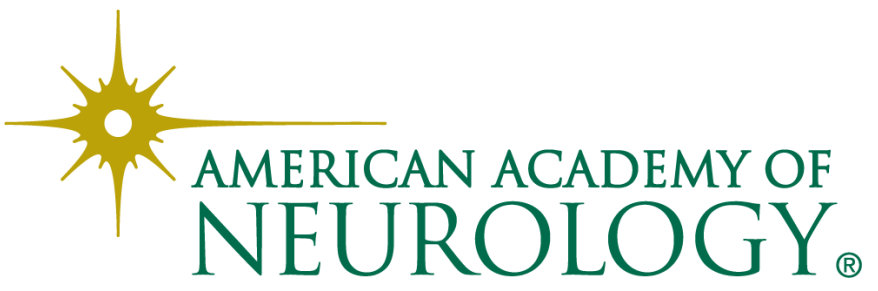

